\title{
Legends of Allergy: Jan E. de Vries
}

\author{
José Carballido ${ }^{1}$ and Hergen Spits ${ }^{2}$ \\ ${ }^{1}$ Novartis Institutes for BioMedical Research \\ ${ }^{2}$ Amsterdam University Medical Centres
}

March 16, 2021

José M. Carballido ${ }^{1}$ and Hergen Spits ${ }^{2}$

${ }^{1}$ Novartis Institutes for Biomedical Research, Translational Medicine, Preclinical Safety, Switzerland

${ }^{2}$ Department of Experimental Immunology, UMC, University of Amsterdam, Amsterdam, The Netherlands.

Jan Egbert de Vries (Figure 1) is a cosmopolitan immunologist and an enthralling mentor with a large track record of innovative achievements in the fields of allergy and immunology. Jan was born in Strijen (NL), a small town located in the Hollands Diep estuary in the South of The Netherlands. He spent his youth in the NL combining his studies with his passion for sports; he became Dutch champion in decathlon. Shortly after his $\mathrm{PhD}$, and like his fellow countryman Erasmus of Rotterdam, he started a long journey that brought him to France, California, Austria and Switzerland, although never settling in any of the cities he worked. Like Erasmus, he has been since an insatiable scholar ("Non est ulla studiorum satietas") and an inspiring mentor for a large number of students and collaborators.

Jan studied at the University of Utrecht (NL) and graduated from the University of Amsterdam (NL) with a $\mathrm{PhD}$ in Immunology in 1976. After his graduation, he spent two years in the lab of John Mendelsohn at the University of California, San Diego (US), as a recipient of an Eleanor Roosevelt fellowship. Thereafter, he returned to Amsterdam, where he became the Head of the Department of Immunology at the National Cancer Research Institute. His groundbreaking observations on the cytotoxic activity of $\mathrm{T}$ lymphocytes isolated from melanoma patients (1) motivated the search for tumor-specific antigens, which could be used for the development of cancer vaccines.

In 1985, Jan took on the position of Director of Immunology at the UNICET- Laboratoires for Immunological Research in Dardilly, a small village near Lyon (FR). UNICET was part of Schering Plough and collaborated closely with the DNAX Research Institute of Molecular and Cellular Biology in Palo Alto (US). It was during that time when Jan became interested in allergy, gaining a notable reputation in the field. Jan made a key contribution to the elucidation of the mechanisms controlling human IgE and IgG4 switching (Figure 2), implicating IL-4 as a key regulator of these processes (2). These were the early days when mouse helper T (Th) cells were segregated as either Th1 or Th2 subsets, following the seminal work of Tim Mossman and Bob Coffman at DNAX. Jan's team observed these distinct phenotypes in human lymphocyte populations isolated from healthy and atopic individuals. However, against the dogma, he also described additional cytokine production profiles aside of the canonical and mutually exclusive IFN- $\gamma$ or IL- 4 secreting types. Now, several decades later, we appreciate the diversity and plasticity of these Th cell responses. Three years in France seemed too long time for this Dutch globetrotter and thus, in 1988, he and his research team moved to DNAX to continue their work in allergy and extend their research to regulatory responses with human $\mathrm{T}$ cells. Jan joined DNAX as the Head of Human Immunology and his work was key in elucidating the biology of IL-10 and IL-13 following their DNA cloning at DNAX. He showed that IL-4 and IL-13 were the triggers for allergic diseases (3) such as asthma, rhinitis and atopic dermatitis, and that IL-10 was a major factor dampening immune responses (4). His team also cloned the signaling lymphocyte activation molecule 
(SLAM/CD150) (5), which gave name to a new family of immune receptors involved in lymphocyte activation. The in vitr o work was expanded to in vivoexperimentation using severe combined immunodeficient (SCID) mice that were reconstituted with human tissues and cells (SCID-hu mice). These studies supported many drug development projects aiming to interfere with allergic responses and/or prevent transplant rejection.

In 1997, Jan was recruited by Novartis as Global Head autoimmune and inflammatory diseases and Head of the Novartis Research Institute (NFI, from its abbreviation in German) in Vienna (AT). Jan led the transition of NFI to the Novartis Institutes for Biomedical Research (NIBR), expanding its original focus on dermatology to autoimmunity and inflammation. Jan was the founder of the Novartis Immunology Platform, a multidisciplinary group focused on the discovery and early development of both therapeutic antibodies and low molecular weight drugs targeting immune checkpoints, cytokines and cytokine receptors, G-proteincoupled receptors and other targets controlling $\mathrm{T}$ cell activation and tolerance induction. In 2008, he became Head of NIBR Europe. During his time in Vienna and Basel, Jan was instrumental for the advancement of many projects, particularly the development of the sphingosine 1 phosphate receptor antagonists FTY720 (Fingolimod/Gilenya@) and BAF312 (Siponimod/Mayzent@) for multiple sclerosis and in championing the clinical testing of immunotherapeutics in psoriasis as early proof of concept, which led to the approval of the anti-IL-17A monoclonal antibody AIN457 (Secukinumab/Cosentyx@). Jan also nurtured the path to initiate antigen-specific immune tolerance projects at Novartis, enabling many collaborations with scientists outside of Novartis.

Jan's remarkable ability to identify transformative opportunities, together with the experience he gained in academic and industrial settings, facilitated his transition from the big pharma industry to biotech. In this new setting, he has been acting as CEO and Chairman of AIMM Therapeutics, Chairman of Cassiopea and CEO of Tr1X, where he is developing cell and gene therapies to cure autoimmune diseases.

The authors of this short biography had the privilege of working with Jan for many years during different steps of his career. We, like many other colleagues who worked side by side with Jan, learned to appreciate Jan's extraordinary scientific insights and people skills. We had the opportunity to witness his passion for science and to learn his innovative way to approach immunology challenges and we remain honored to count on him as a source for inspiration and as a good friend.

Major contributions

- Discovery of cytotoxic tumor-specific cytotoxic T cell clones from melanoma patients

- Cloning of human IL-4 and IL-13 and elucidation of their roles in the regulation of IgE production by human B cells

- Cloning and characterization of human IL-10 and demonstration of its profound immune-suppressive effects

- Development of Gilenya $\AA$ and Mayzent $($, and of Cosentyx $₫$ for the treatment of multiple sclerosis and psoriasis, respectively

References

1. de Vries JE, Spits H. Cloned human cytotoxic T lymphocyte (CTL) lines reactive with autologous melanoma cells. I. In vitro generation, isolation, and analysis to phenotype and specificity. J Immunol1984;132 :510-519.

2. Pène J, Rousset F, Briere F, Chrétien I, Bonnefoy JY, Spits H et al. IgE production by normal human lymphocytes is induced by interleukin 4 and suppressed by interferons gamma and alpha and prostaglandin E2.Proc Natl Acad Sci USA 1988;85:6880-6884.

3. Punnonen J, Aversa G, Cocks BG, McKenzie AN, Menon S, Zurawski G et al. Interleukin 13 induces interleukin 4-independent IgG4 and IgE synthesis and CD23 expression by human B cells. Proc Natl Acad Sci USA 1993;90 :3730-3734.

4. de Waal Malefyt R, Abrams J, Bennett B, Figdor CG, de Vries JE. Interleukin 10(IL-10) inhibits cytokine 
synthesis by human monocytes: an autoregulatory role of IL-10 produced by monocytes. J Exp Med1991;174 :1209-1220.

5. Cocks BG, Chang C-CJ, Carballido JM, Yssel H, de Vries JE, Aversa G. A novel receptor involved in T-cell activation. Nature 1995;376:260-263.

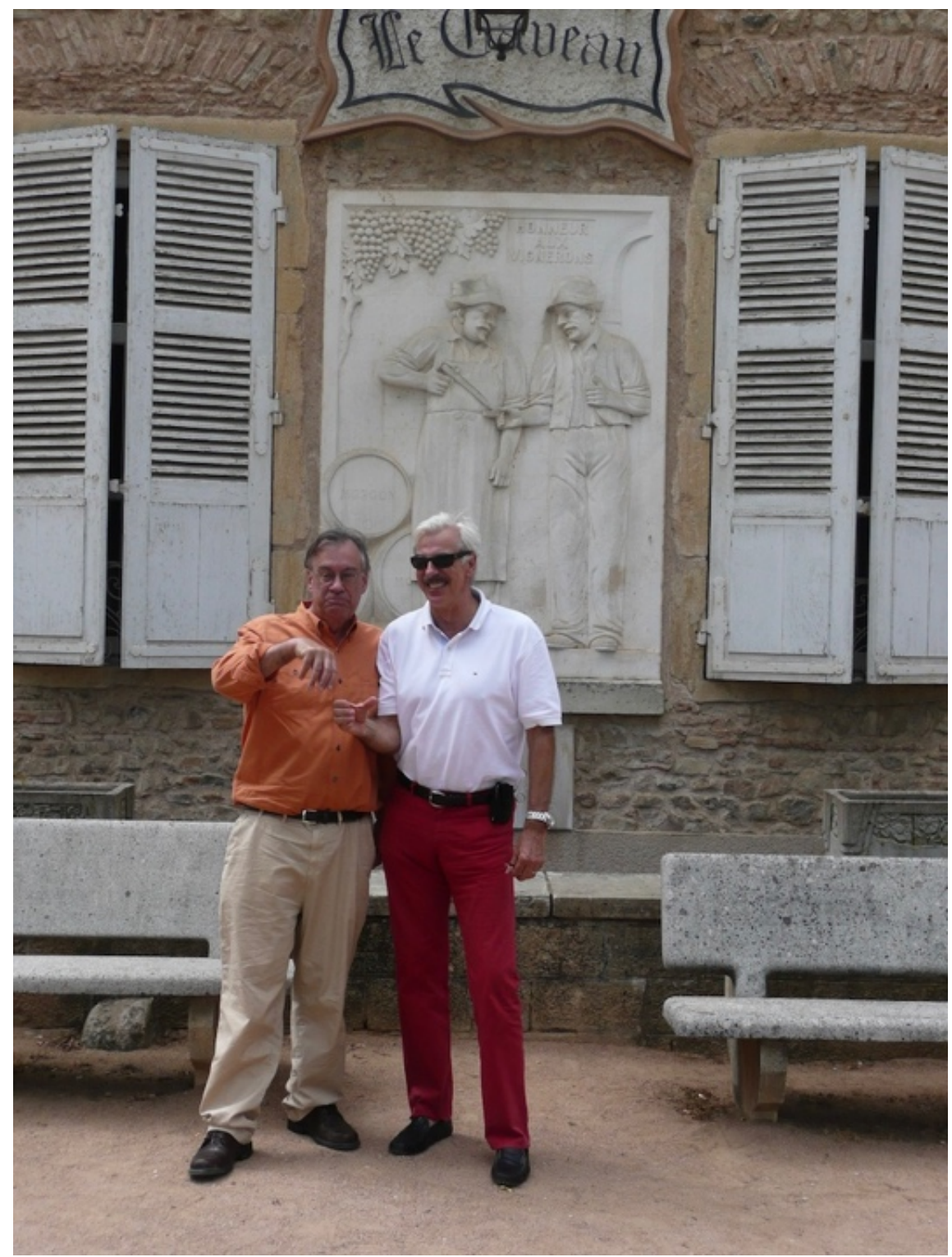




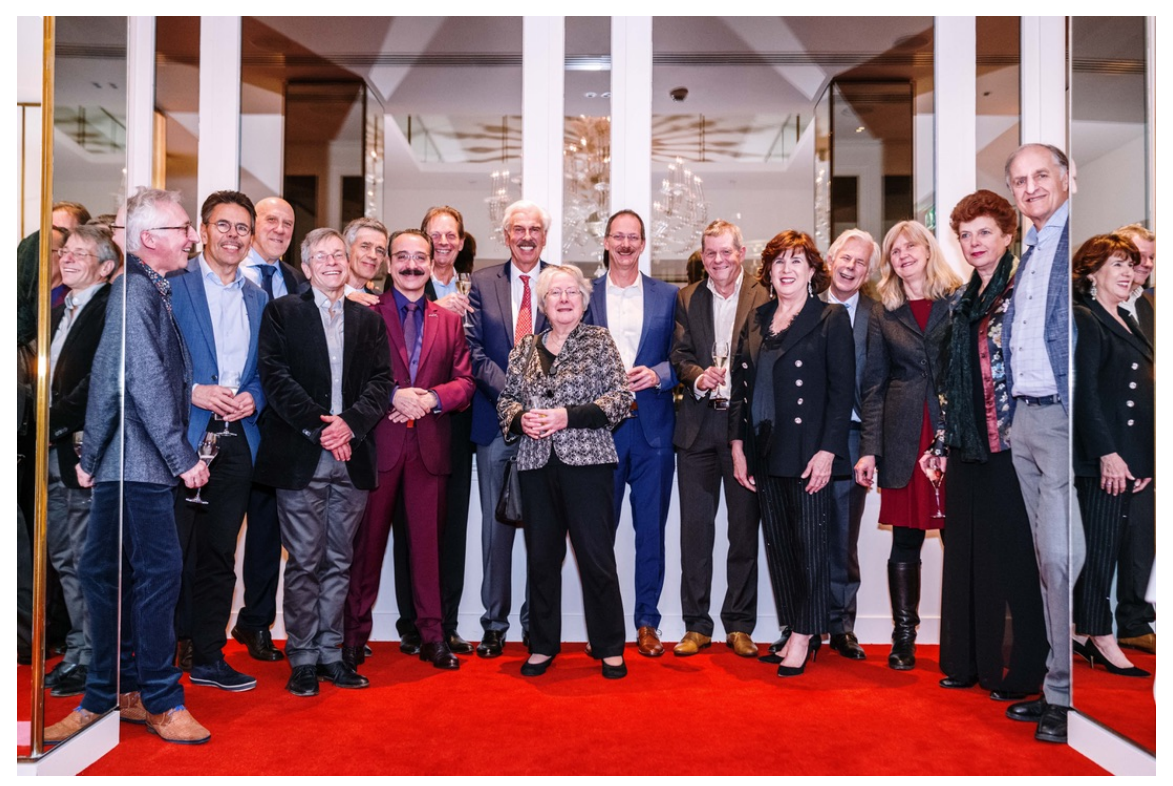

FIGURE 1 Jan E. de Vries $\left(2^{\text {nd }}\right.$ and $8^{\text {th }}$ from left, in left and right pictures, respectively) with some of his collaborators and mentees.

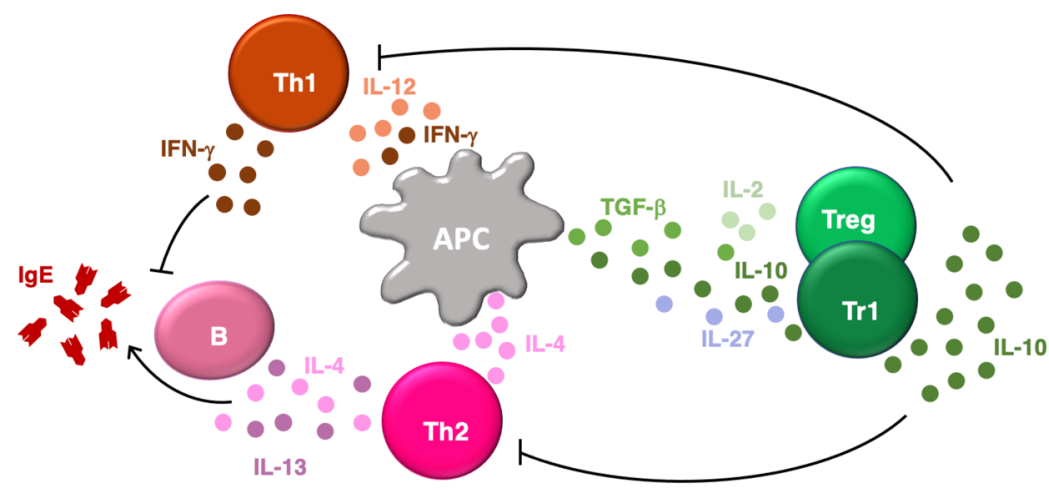

FIGURE 2 Among other milestones, Jan described the mechanisms regulating human IgE switching associated to allergic diseases and the potent dampening effects of IL-10 on broad immune responses. 